\title{
Marcha das Margaridas: Participação política, empoderamento e movimento social em rede das mulheres do campo e da floresta
}

\author{
Manuella Paiva de Holanda Cavalcanti \\ Mestre em Sociologia pela Universidade Federal Fluminense \\ Eden Erick Hilário Tenório de Lima \\ Professor na Universidade Estadual de Ciências da Saúde de \\ Alagoas \\ Doutorando em Ciências Sociais / UFCG
}

Resumo: Temos como foco analisar a partir da Marcha das Margaridas a participação política, o empoderamento feminino e a articulação em rede desse movimento social. Que se caracteriza por ser multiforme, pluritemático e interorganizacional. Portanto, é uma rede de movimento definida por práticas políticas que enlaçam os três níveis articulatórios do movimento em rede como também os três componentes da construção política, de acordo com SchererWarren. O empoderamento das mulheres ocorre no nível intrapessoal e comunitário. E a participação política dessas mulheres do campo e da floresta proporcionam visibilidade enquanto sujeitos políticos, terem voz e decisão na produção das pautas da Marcha e poder de ação na construção dos assuntos que lhe afetam. Assim, percebemos que a participação política e o empoderamento dessas mulheres a partir das ações da Marcha modificam sua vida no nível individual e coletivo.

Palavras-chave: Marcha das Margaridas; Movimentos sociais em rede; Empoderamento de mulheres. 


\title{
March of Margaridas: Political participation, empowerment and social moviment networking of women's field and forest
}

\begin{abstract}
Beginning in 'Marcha das Margaridas', the text below analyzes the political participation, the feminine empowerment and the articulation of this social movement. It is possible to emphasize some characteristics, typical from this movement: differents thematics to work on,multiform and interaction between other organizations. Therefore, 'Marcha das Margaridas' is a net of movement defined by policy practices including the three levels of movement articulation as also the three elements of policy constructions, according to Scherer-Warren. The empowerment of women happens in interpersonal and communitarian level and the political participacion of these women from the field and forest provides visibility as political subject. They have voice and decision to produce the Marcha guidelines and power of action to build the subject that affect them. Therefore, we realized that the political participacion and the empowerment of these women through the 'Marcha das Margaridas' changes their lifes in individual and collective level.
\end{abstract} women.

Keywords: March of Margaridas; social movement net; empowerment of

\section{Marcha de las Margaritas: la participación política, la participación y la creación de redes movimiento social del campo y el bosque de las mujeres}

Resúmen: Se analiza la Marcha de las Margaritas; su participación política, el empoderamiento femenino y la articulación en redes de este movimiento social. El cual se caracteriza por ser multiforme y pluritemático entre las organizaciones. Por lo tanto, es un sistema de movimiento definido por prácticas políticas que vinculan los tres niveles de articulación en forma de red, de acuerdo con los tres componentes de construcción política, según SchererWarren. El empoderamiento de las mujeres ocurre en los niveles intrapersonal y comunitario, y la participación política de las mujeres del campo y el bosque proporcionan visibilidad como sujetos políticos; tienen voz y decisión en la producción de las agendas de la Marcha y poder de acción en la construcción de las cuestiones que les afectan. Asimismo, nos damos cuenta que la participación política y empoderamiento de las acciones de la Marcha cambian de nivel individual y colectivo.

Palabras clave: Marcha de las Margaritas; Red de movimientos sociales; Empoderamiento de las mujeres. 


\title{
Introdução
}

\begin{abstract}
Rompemos com a invisibilidade que nos foi imposta durante tantos anos de nossas vidas e às gerações que nos antecederam, para fazermos presentes nos espaços políticos, dizer a que viemos, o que queremos e incidirmos nos rumos econômicos, sociais e ambientais do nosso país, com igualdade para as mulheres. (Cadernos de textos da Marcha das Margaridas, 2011, p.5)
\end{abstract}

Há alguns anos, os movimentos feministas vêm reivindicando diversos direitos para as mulheres e lutando pela igualdade de gênero. Estes movimentos têm mostrado diversas facetas, bem como distintas bandeiras de lutas e pautas diferenciadas. Evidenciam, dessa forma, a pluralidade de sujeitos, como ocorre com a multiplicidade de mulheres do campo e da floresta. Por não terem suas bandeiras de lutas erguidas e pautas abarcadas em outros movimentos sociais, inclusive o próprio movimento rural mais geral, elas vão às ruas, lutam por seus direitos e instituem, juntamente com outros movimentos, a Marcha das Margaridas.

Intencionamos compreender a atuação dessas mulheres, a partir da Marcha das Margaridas - uma ação estratégica das mulheres do campo e da floresta que faz parte da agenda permanente do Movimento Sindical de Trabalhadores e Trabalhadoras Rurais-MSTTR e diversos movimentos feministas e de mulheres. Destarte, buscamos, portanto, analisar como a participação política e social afeta diretamente a vida dessas mulheres e também como esta participação é importante para o empoderamento e mudanças nas relações sociais em que se inserem ou ainda como elas conseguem fazer uma articulação em rede desse movimento, mostrando assim a força de organização e mobilização para garantir seus direitos.

Desse modo, organizamos este artigo da seguinte forma: inicialmente fizemos algumas considerações a respeito das questões de gênero e o mundo rural, posteriormente traçamos um breve panorama histórico sobre a Marcha das Margaridas; em seguida analisamos alguns elementos desta marcha na organização em rede de movimentos sociais rurais, e por fim, compreendemos a participação política e empoderamento dessas mulheres.

\section{Gênero e mundo rural}

A dinâmica do mundo rural nas sociedades contemporâneas está em constante transformação. E para abarcar esta realidade, distintas teorias surgem como forma de explicação e compreensão dessa realidade. Algumas vertentes enfatizam que o "processo de urbanização nas localidades rurais" (CARNEIRO, 2008, p.11) juntamente com outras mudanças acarretariam o fim do mundo rural. Contudo algumas correntes se contrapõem a essa afirmação e enfatizam que esse espaço está se resignificando, ou seja, há o "um novo ruralı" em que novas sociabilidades estão surgindo. É nesse contexto que compreendemos as ações das trabalhadoras rurais do campo e da floresta. Ao reivindicarem seus

1 Sabemos que os autores dão novo sentidos e significados a essa expressão. No entanto, tomamos aqui emprestado para pensar as novas sociabilidades femininas no meio rural. Que, para nós, também podem ser pensadas a partir desta concepção. 
direitos políticos e sociais, elas dão vida a novos sujeitos, no entanto, dentro da própria estrutura do espaço rural. Elas não negam suas identidades do campo e da floresta, ao contrário, afirmam esta identidade para que assim possam lutar por seus direitos. Tanto nas questões de igualdade de gênero como por terra, previdência, saúde e educação.

Para pensar os elementos com os quais essas mulheres buscam romper, traremos para o centro do debate algumas reflexões de Carneiro, orientando o olhar para "reconhecer as relações de força entre agentes sociais situados diferentemente na esfera do parentesco (se filho (a), esposa e marido) e da produção" (CARNEIRO, 2008a, p. 259). Sendo assim, é necessário compreender as diferentes posições e papéis ocupados por esses membros da família, sobretudo no que se refere às relações de gênero no ambiente familiar. É importante destacar que não estamos falando aqui de mulheres, homens e modelos de família universal. Compreendemos as particularidades, mesmo dentro do meio rural, das distintas formas de organização dessas famílias. Enfatizamos também que a realidade, a que nos referimos já esteja em processo contínuo de mudanças e transformações. No entanto, traremos algumas particularidades recorrentes e importantes para pensar porque essas mulheres marcham e as formas de opressão que elas vivenciam ou vivenciaram.

Assim, Carneiro (2008a) apresenta que dentro dessa estrutura e hierarquia familiar do mundo rural o pai é o provedor, responsável pela partilha da terra e privilegia os herdeiros. Dessa forma, consolida relações assimétricas entre os gêneros, visto que na maioria das vezes a herança é dada aos filhos homens. Dito isso, a autora afirma que, se os bens materiais são responsabilidade dos homens, que ocupam a esfera da produção, às mulheres cabe a reprodução da vida, isto é, a transmissão dos bens simbólicos e, quando estas fazem o trabalho na produção são tidas como ajudantes e/ou cooperadoras de seus maridos. O lugar ocupado pela mulher é na maioria dos casos tido como secundário tanto por homens como pelas próprias mulheres.

Outro ponto importante é a questão de quem tem direito ao título de domínio e a concessão de uso da terra. Apesar da Constituição de 1988, que preconiza que o direito seja exercido igualmente por homens e mulheres, na prática, algumas pesquisas demonstram que "o acesso limitado à terra continua sendo um dos principais obstáculos para a participação integral da mulher no desenvolvimento rural e, consequentemente, na melhoria das condições de vida das mulheres e das crianças" (CARNEIRO, 2008a, p. 262).

A partir dessas constatações, entendemos que as mulheres do campo e da floresta, ao se mobilizarem na Marcha das Margaridas, buscam garantir o direito ao acesso à propriedade de terra, rompendo com a subordinação na hierarquia familiar e garantir a visibilidade de sua condição na luta por espaços de participação política.

\section{Breve histórico da Marcha das Margaridas}

A Marcha das Margaridas é uma ação estratégica das mulheres do campo e da floresta. Faz parte da agenda permanente do Movimento Sindical de Trabalhadores e Trabalhadoras Rurais e diversos movimentos feministas e de mulheres. É coordenada pelo MSTTR e composta pela Confederação Nacional 
de Trabalhadores na Agricultura (CONTAG). Fazem parte ainda, mais 27 Federações de trabalhadores e trabalhadoras da Agricultura (FETAG'S) e mais de 4000 sindicatos, além de inúmeros parceiros, conforme expresso na cartilha da MM.

São parceiras da Marcha das Margaridas:

- Movimento da Mulher Trabalhadora Rural do Nordeste MMTRNE;

- Movimento Interestadual das Quebradeiras de Coco Babaçu MIQCB;

- Conselho Nacional Agroextrativista - CNS;

- Movimento Articulado das Mulheres da Amazônia - MAMA;

- Marcha Mundial das Mulheres - MMM;

- Articulação de Mulheres Brasileiras - AMB;

- União Brasileira de Mulheres - UBM;

- Central Única dos Trabalhadores - CUT;

- Central dos Trabalhadores e Trabalhadoras do Brasil - CTB;

- Rede de Mulheres da América Latina e do Caribe - Rede Lac;

- Confederação Internacional de Organizações de Produtores Familiares, Campesinos e Indígenas do Mercosul Ampliado (COPROFAM).

O nome da Marcha é em homenagem a dirigente sindical Margarida Alves (1943-1983) que ocupou por 12 anos a presidência do Sindicato dos Trabalhadores e Trabalhadoras Rurais de Alagoa Grande (PB). Por sua luta em favor dos direitos dos trabalhadores e trabalhadoras rurais foi brutalmente assassinada, mas deixou um legado de luta e resistência que permanece até os dias atuais.

Quando as Margaridas foram às ruas, em 2000, levaram indignação e vontade de justiça. A morte de Margarida Alves e a constituição do movimento evidenciam a realidade e luta de muitas mulheres. Após 18 anos do seu homicídio e a impunidade dos assassinos, as integrantes da Marcha das trabalhadoras rurais homenagearam a líder sindical e colocaram seu nome no ato de maior expressão e visibilidade das mulheres rurais. A luta dessas mulheres não começou naquele momento, pelo contrário, foi a participação política e empoderamento dessas mulheres, que já faziam parte de diversos outros movimentos e sindicatos que possibilitou a afirmação dessa história. Justamente por reconhecer as amarras que as prendem e pela consciência política adquirida, que esse movimento ganhou força e voz, que está vivo, latente e crescente nos dias atuais.

As Margaridas estão lutando por suas terras, sua autonomia econômica, pelo fim da violência sexual e tantas outras pautas e dessa forma estão plantando e colhendo seus frutos. Há quatorze anos essa mobilização vem acontecendo. A primeira Marcha ocorreu em 2000, e desde então se percebe a grande mobilização e organização dessas mulheres. Com o lema "2000 razões para Marchar contra a fome, a pobreza e a violência sexista, foi construída a primeira Marcha das Margaridas articulada com a Marcha Mundial das Mulheres" (CONTAG, 2008, p.9)". De acordo como a CONTAG, neste primeiro encontro estavam presente cerca de 20 mil participantes, na capital do Brasil. 
A Segunda Marcha das Margaridas ocorreu em 2003, e o lema foi "2003 razões para lutar por terra, água, salário, saúde e contra a violência” (SILVA, 2008, p. 99). Esta contou com a participação de 40 mil pessoas. Já em 2007, foi realizada a terceira edição e a cada ano as Margaridas ocupam mais as ruas. Nesta edição havia cerca de 50 mil pessoas e o lema foi: "construindo 2007 razões para marchar contra a fome, a pobreza e a violência sexista" (SILVA, 2008, p.86). E como tema: Terra, água e agroecologia; segurança alimentar e nutricional e a construção da soberania alimentar; trabalho, renda economia solidária; garantia de emprego e melhores condições de vida e trabalho das assalariadas; política de valorização do salário mínimo.

A expectativa era "empreender um processo político organizativo e educativo no qual as trabalhadoras, pudessem analisar as causas de sua dominação" (CONTAG, 2007, p. 7). Já no aspecto político econômico o intuito era "fortalecer a organização das mulheres nos espaços públicos, estaduais, nacionais e internacionais ampliando a capacidade de propor, articular e reivindicar alternativas que atendam as necessidades e demandas das trabalhadoras rurais" (CONTAG, 2007, p. 7). É importante destacar que as pautas de 2007 de certa forma atualizaram os temas das Marchas anteriores possibilitando melhor qualificá-los e assim poder propor e encaminhar demandas ao governo federal.

As três primeiras Marchas consolidaram-se pela luta contra a fome, a pobreza e a violência sexista, já a quarta edição realizada em 2011 teve como lema "Desenvolvimento sustentável com justiça, autonomia e liberdade" (CONTAG, p.5). E a plataforma política articulava os seguintes eixos: biodiversidade e democratização dos recursos ambientais; terra, água e agroecologia; soberania e segurança alimentar e nutricional; autonomia econômica, trabalho e renda; educação não sexista e violência; saúde e direitos reprodutivos; democracia, poder e participação política. A partir dessas reivindicações, esta Marcha visa dar visibilidade as distintas realidades das mulheres trabalhadoras do campo e da floresta, buscando "conquistar recursos e políticas para vencer a pobreza e a desigualdade com respeito às tradições, culturas e saberes, a proteção à biodiversidade, ao patrimônio genético e aos bens comuns." (CONTAG, p.11). Esta teve participação de setenta mil mulheres do campo da floresta.

A Marcha das Margaridas configura-se em uma ação política, visto que é neste espaço que as mulheres trabalhadoras rurais ganham visibilidade e reconhecimento social. A partir das estratégias políticas da mobilização da Marcha, estas mulheres trazem para o centro do debate a importância econômica e política de suas ações no campo e na floresta. Sendo o momento em que apresentam suas reivindicações para que, a partir delas e de outros elementos, suas questões possibilitem formulações de políticas públicas que garantam o acesso das "mulheres a terra, assistência técnica, crédito, políticas sociais e direitos de cidadania" (CONTAG, 2008, p.9). Desde a primeira edição, a Marcha é um espaço de formação, denúncias, proposições e negociações como o governo federal. Com a consolidação das quatro2 Machas é possível perceber a importância política desta ação, sobretudo, na luta do movimento sindical das mulheres. Produzindo, portanto, um grande amadurecimento dessa organização

2 Gostaríamos de ressaltar que em 2015 ocorreu a quinta edição da Marcha das Margaridas, no entanto esta não é objeto desta investigação. Visto que no momento em que escrevíamos este artigo não tínhamos material suficiente para análise. Assim, nos atemos as marchas de 2000, 2003, 2007 e 2011. 
na luta pela igualdade de gênero, como um desenvolvimento sustentável e justo tanto no campo como na cidade. Percebe-se, assim a participação e engajamento das mulheres em questões, econômicas, políticas e sociais. Conforme podemos verificar nos objetivos políticos propostos por elas no decorrer das quatro edições da Marcha.

Dito isso, de acordo com o último caderno de textos da Marcha das Margaridas para construção do quarto ato, os objetivos políticos da MM são:

- Fortalecer e ampliar a organização, mobilização e formação sindical e feminista das mulheres trabalhadoras rurais;

- Contribuir para a democratização das relações no MSTTR, com a superação das desigualdades de gênero;

- Atuar para que as mulheres do campo e da floresta sejam protagonistas de um novo processo de desenvolvimento rural voltado para a sustentabilidade da vida humana e do meio ambiente;

- Dar visibilidade e reconhecimento à contribuição econômica, política, social das mulheres no processo de desenvolvimento rural;

- Denunciar e protestar contra a fome, a pobreza e todas as formas de violência, exploração, discriminação e dominação e avançar na construção da igualdade para as mulheres;

- Propor e negociar políticas públicas para as mulheres do campo e da floresta.

Estes objetivos políticos são amplos e incluem diversas pautas para superar a desigualdade de gênero. A realização das quatro Marchas possibilitou algumas conquistas para essas mulheres. São as seguintes, segundo Gois (2012):

- Documentação e acesso a terra, apoio às mulheres assentadas e políticas de apoio a produção na agricultura familiar;

- criação do Programa Nacional de Documentação da Mulher Trabalhadora Rural (PNDMTR) e fortalecimento do mesmo com ações educativas e unidades móveis em alguns estados;

- Titulação Conjunta Obrigatória e revisão dos critérios de seleção de famílias cadastradas para facilitar o acesso das mulheres a terra;

- estabelecimento de normas para efetivar o direito das trabalhadoras rurais ao Programa Nacional de Reforma Agrária, dentre elas a prioridade às mulheres chefes de família;

- capacitação de servidores do INCRA sobre legislação e instrumentos para o acesso das mulheres a terra;

- formação do Grupo de Trabalho (GT) sobre Gênero e Crédito e a Criação do Programa de Apoio à Agricultura Familiar (PRONAF) Mulher;

- criação do crédito instalação para mulheres assentadas;

- Declaração de Aptidão ao PRONAF em nome do casal;

- ações de Capacitação sobre PRONAF;

- inclusão da abordagem de gênero na Política Nacional de Assistência Técnica e Extensão Rural (ATER); 
- apoio ao protagonismo das mulheres trabalhadoras nos territórios rurais;

- criação do Programa de Apoio a Organização Produtiva das Mulheres;

- apoio para a realização de feiras para comercialização dos produtos dos grupos de mulheres;

- manutenção da aposentadoria das mulheres aos 55 anos;

- representação na Comissão Tripartite de Igualdade de Oportunidades do Ministério do Trabalho;

- Campanha Nacional de Enfrentamento a Violência contra as Mulheres do Campo e da Floresta;

- criação e funcionamento do Fórum Nacional de Elaboração de Políticas para o Enfrentamento à Violência contra as Mulheres do Campo e da Floresta;

- elaboração e inserção de diretrizes na Política Nacional de Enfrentamento à Violência contra as mulheres voltadas para o atendimento das mulheres rurais;

- criação da Coordenadoria de Educação do Campo no Ministério de Educação (MEC);

- implementação do Projeto de Formação de Multiplicadoras(es) em Gênero, Saúde e Direitos Sexuais e Reprodutivos em convênio com o Ministério da Saúde;

- reestruturação do Grupo Terra responsável pela construção da política de saúde para a população do campo.

Assim, percebemos que as mulheres do campo e da floresta ganharam visibilidade e estão marchando no caminho por igualdade de direitos. A partir dessa caminhada já obtiveram algumas conquistas, mas ainda há inúmeras reivindicações feitas e a serem conquistadas. Elas estão mostrando que com participação social e engajamento na luta política há possibilidade de mudança nas estruturas e nas relações sociais em que estão inseridas.

\section{Marcha das Margaridas e movimentos rurais em rede}

Podemos inferir que a Marcha das Margaridas de acordo com SchererWarren caracteriza-se como uma organização da sociedade civil denominada de "mobilização na esfera pública", ou seja, são decorrentes da articulação dos movimentos sociais localizados, dos fóruns e rede de redes, que têm no espaço público a grande força de sua expressão. É através das ações na rua que buscam visibilidade e dessa forma exercem pressão política extremamente expressiva na esfera pública na atualidade. Constituindo, assim, articulação em rede de movimentos sociais. Isto é, a articulação com outros grupos que compartilham valores e objetivos comuns, com afinidade política e social. Segundo SchererWarren "esse processo articulatório, atribuem, portanto, legitimidade às esferas de mediação (fóruns e redes) entre os movimentos localizados e o Estado, por 
um lado, e buscam construir redes de movimento com relativa autonomia, por outro." (SCHERER-WARREN, 2006, p.113-114).

Do ponto de vista organizacional, inclui várias redes de redes; desde a CONTAG, até a FETAG's e o MSTTR, com outros movimentos específicos de mulheres que têm muitos pontos de pautas em comum. E dessa forma, se aglutinam em torno de melhor alcançarem seus objetivos. Já do ponto de vista da ação movimentalista expressam algumas dimensões que definem o movimento social. Expressando três componentes de construção política, segundo Scherer-Warren (2007) tal como: o princípio de Identidade; de gênero e de classe - mulheres trabalhadoras rurais do campo e da floresta, um adversário ou definição de um conflito, combater a fome, a pobreza e a violência sexista entre outros, e por um projeto de mudança garantir o acesso das mulheres a terra, assistência técnica, crédito, políticas sociais e direitos de cidadania.

A MM articula, assim, várias escalas organizacionais do local ao regional, ao nacional e ao transacional. Representada em três níveis que constitui um movimento em rede: no organizacional articula a rede com entidade e movimentos específicos, como o MIQB, MAMA. É o momento da construção da identidade política e coletiva entre os fóruns e as redes. No nível político ocorre a ampliação do debate nos fóruns e rede organizacionais, nos encontros locais, regionais, organizados pelas FETAG's e nacionais promovidos pela CONTAG, CUT, CTB; este nível tem um papel político estratégico por possibilitar o intercâmbio entre diversos movimentos e principalmente, por ser um espaço que possibilita formular questões para propor políticas públicas. E por fim, no último nível, o mobilizatório, há a realização da própria Marcha das Margaridas, buscando a visibilidade política, o reconhecimento público e abrir canais de negociações na esfera pública. De acordo com Ilze Scherer-Warren,

\begin{abstract}
a rede de movimentos sociais se define como o conjunto das práticas políticas formadas pelos três níveis organizacional, articulatório e de mobilização, transcendendo as expressões meramente empíricas desses níveis rumo à construção de uma lógica de movimento que inclui a construção identitária da luta, a definição de adversários ou opositores sociais ou sistêmicos, em nome de um projeto ou utopia de transformação social, cultural, política ou sistêmica. (SCHERER-WARREN, 2007, p. 3).
\end{abstract}

Desse modo, a MM é uma rede de movimento social definida por práticas políticas que enlaça tanto os três níveis articulatórios do movimento em rede como também os três componentes da construção política, conforme mencionamos anteriormente.

A articulação do movimento em rede permite ainda perceber que a atuação da Marcha das Margaridas parte do princípio da existência da discriminação de gênero, ou seja, uma pauta mais específica e soma-se às questões mais gerais dos movimentos em rede. Por isso, tem uma plataforma política mais ampla e multidimensional, sendo construída pelos diversos grupos envolvidos em todo território nacional, tendo assim uma interface com os mais variados movimentos e sindicatos. Segundo Aguiar:

A atuação dos movimentos em rede permite, assim, à Marcha extrapolar a delimitação do raio de ação de movimentos que atuam em espaços mais localizados como Movimento Articulado de Mulheres da Amazônia (MAMA) ou o Movimento Interestadual das Quebradeiras de Coco Babaçu (MIQCB). Ao desenvolver estratégias políticas e propostas programáticas em torno de suas necessidades e de sua noção de direitos a Marcha conecta os espaços locais com espaços regionais, nacionais e até 


\begin{abstract}
internacionais. Além disso, a construção de estratégias consensuais entre os diversos movimentos, organizações e redes que a compõem fortalece sua posição na negociação frente ao Estado, e também frente ao movimento sindical, visto que a grande maioria das mulheres é vinculada aos sindicatos de trabalhadores e trabalhadoras rurais, inseridos no sistema CONTAG. E por fim, as interconexões dentro do próprio movimento, mas também com outros movimentos e redes de movimentos, como por exemplo, a Marcha Mundial de Mulheres, tem favorecido tanto a expressão do mal-estar com as assimetrias de gênero, como a possibilidade de melhorar as relações de gênero no interior do próprio movimento sindical. (AGUIAR, 2013, p.4).
\end{abstract}

Portanto, a Marcha mantém tanto ponto específico, como também pautas do projeto mais geral que unem todos os movimentos envolvidos. Sendo assim, caracteriza-se por ser multiforme, pluritemáticos e interorganizacionais. Dessa forma, as redes aproximam diferentes atores sociais, das mais diversas organizações e constroem diálogos coerentes que possibilitam a união desta rede. Permitindo a defesa de um sujeito plural. Bem como o empoderamento das mulheres do campo e da floresta e ainda uma maior participação política, não só no que se refere às questões de gênero, mas de um projeto político, econômico, cultural e social.

\title{
Participação Política e empoderamento das mulheres
}

A Marcha das Margaridas vem se consolidando como um movimento de mulheres que cada vez mais fortalece a democracia participativa no Brasil. Sendo fruto da resistência e luta de diversos outros movimentos feministas que buscam a efetivação das mulheres nos espaços políticos, bem como seu reconhecimento e representação em cargos de direção em sindicatos, movimentos sociais, no executivo, legislativos enfim em todas as esferas da vida pública. Este movimento já alcançou algumas conquistas em relação à participação das mulheres nos espaços públicos, sobretudo de visibilidade e também de ocupação de cargos nos sindicatos e nos diversos outros movimentos específicos.

Gilva Maria Rodrigues, Coordenadora das mulheres FETAG do Distrito Federal, afirma "que a Marcha ajuda na organização das mulheres. A política sindical se fortalece em $80 \%$ com a Marcha das Margaridas. Com as mobilizações, as mulheres se veem como protagonistas da vida política e sindical" (CONTAG, 2008, p.46).

Dito isso, a participação das mulheres nos movimentos sociais e sindicatos possibilita tanto a inclusão nos espaços públicos como resignificar seu papel na estrutura familiar, na comunidade e em todos os espaços que ocupa. Redefinindo, a própria relação dessas mulheres no espaço público e privado.

De acordo com Amorim,

\footnotetext{
através do engajamento nos movimentos, as mulheres rurais alcançam novas significações tanto no âmbito privado quanto no público e essa nova posição se dá logo no momento de sua adesão. [...]a adesão pode ser pensada como um rito de passagem do mundo privado para o mundo público, colocando o sujeito frente a novas relações de poder e, consequentemente, de tensão no interior da família, do local de trabalho, nas relações de afeto e vizinhança. De fato, tal atitude rompe tabus e preconceitos e coloca em voga novos valores e comportamentos desafiando relações de poder, principalmente em locais resistentes à participação da mulher no espaço público. (AMORIN, 2010, p.6).
} 
A partir do exposto, percebe-se que a participação nos movimentos sociais abre um leque diverso de mudanças na vida não só dessas mulheres, mas também possibilita mudanças no meio social a qual elas estão inseridas. A participação na esfera pública amplia os horizontes, contudo também é permeada de conflitos e contradições. Percebemos isso a partir da fala da coordenadora estadual de mulheres da FETAET - Tocantins. Para ela, "há muita resistência por parte dos homens na participação das mulheres. A Marcha das Margaridas ajuda a quebrar essas barreiras. Nós queremos trabalhar como iguais na luta dos movimentos sindical e sociais." (CONTAG, 2008, p.43). Inferimos, assim, que a Marcha é um espaço de engajamento que possibilita a transformação na vida dessas mulheres e também é o espaço de lutas e resistência dentro do próprio movimento social mais geral. Possibilitando romper ou causar fissuras na estrutura patriarcal da nossa sociedade, além é claro, de ampliar o debate e a participação das mulheres na esfera pública. Conforme expressa Maria das Neves, coordenadora da FETAG - Paraíba, para ela na Macha "é importante mostrar aos companheiros homens que as mulheres têm seus valores e força para se organizar e mostrar seus desejos na luta" (CONTAG, 2008, p.44).

A MM além de problematizar a questão da participação política também possibiliza o empoderamento3 dessas mulheres do campo e da floresta. Assim:

\begin{abstract}
empoderar é o processo pelo qual indivíduos, organizações e comunidades angariam recursos que lhes permitam ter voz, visibilidade, influência e capacidade de ação e decisão. Nesse sentido, equivale aos sujeitos terem poder de agenda nos temas que afetam suas vidas. Como o acesso a esses recursos normalmente não é automático, ações estratégicas mais ou menos coordenadas são necessárias para sua obtenção. Ademais, como os sujeitos que se quer ver empoderados muitas vezes estão em desvantagem e dificilmente obtiveram os referidos recursos espontaneamente, intervenções externas de indivíduos e organizações são necessárias, consubstanciadas em projetos de combate à exclusão, promoção de direitos e desenvolvimento, sobretudo em âmbito local e regional, mas com vistas à transformação das relações de poder de alcance nacional e global. Trata-se, portanto, da promoção de direitos de cidadania. (HOROCHOVSKI, 2007, p.2)
\end{abstract}

Destarte, compreendemos que a Marcha proporciona visibilidade às mulheres enquanto sujeitos políticos, através do poder voz e decisão na construção das pautas, ou seja, poder de ação na construção dos assuntos que lhe afetam. Nesse sentindo propõem questões que podem vir a compor a agenda de governo.

Ainda há ações estratégicas em nível local e regional para fortalecer o próprio movimento e possibilitar ações mais gerais no movimento nacional. Segundo a coordenadora Estadual das Mulheres de Alagoas, Rilda Gezuíno, "no processo de mobilização, fizemos um seminário estadual para incluir na pauta da Marcha as dificuldades enfrentadas pelas companheiras alagoanas, que são, principalmente, questões ligadas à previdência e à violência" (CONTAG, 2008, p.43), ou seja, inicialmente a articulação da rede local, para então ampliar este empoderamento no nível nacional. Sendo assim, podemos classificar esta participação das mulheres nos mais diversos níveis organizacionais, como empoderamento em nível comunitário. Isto quer dizer, são ações desenvolvidas por meios de processos coletivos para atingir seus objetivos. E dessa forma, capacitando "grupos ou indivíduos desfavorecidos para a articulação de

3 Não temos por intuito aqui fazer uma grande definição desse conceito, visto seu carácter polissêmico, mas apenas elucidar de forma coerente e desse modo poder trazer algumas questões importantes a respeito da MM. 
interesses, buscando a conquista plena dos direitos de cidadania, defesa de seus interesses e influenciar ações do Estado" (BAQUERO, 2012, p. 177). Como bem expressa a coordenadora estadual de mulheres da FETASE, Lúcia Moura, "o governo precisa olhar a pauta da Marcha com muito cuidado, pois cada item tem o pensamento e a angústia das mulheres do Brasil. Precisamos estar lá discutindo e ajudando o governo a entender e ver que não basta ir a Brasília, mas que temos nossas necessidades nas nossas comunidades e municípios." (CONTAG, 2008, p.45).

Além do empoderamento em nível comunitário, outro fluxo de empoderamento também é ativado. É o que alguns autores denominam de nível individual. São aqueles que acontecem nos sujeitos no nível intrapessoal. É a capacidade que essas mulheres têm de serem protagonistas de suas vidas, ganharem conhecimento de suas forças pessoais e lutarem pela conquista de seus direitos. No entanto, isso ocorre mediante a participação dessas mulheres nos movimentos e sindicatos e em outras esferas.

Na MM elas ganham força e se fortalecem individualmente com a ação do coletivo e desse modo são capazes de influenciar e fortalecer os movimentos que fazem parte. Desse modo, para Lérida Pavamelo, coordenadora estadual de Mulheres do Rio Grande do Sul, as "mulheres que foram para Marcha foram bem conscientes do que se tratava e do que era a Marcha das Margaridas. A Marcha mexe com as mulheres. Quando elas voltam desses eventos estão com vontade de ação" (CONTAG, 2008, p.48).

Assim, entendemos que a participação política é o empoderamento dessas mulheres do campo e da floresta, a partir das ações da Marcha, ocasiona modificações em suas vidas a nível individual e coletivo. Contudo, isso não ocorre em ações espontâneas, mas nas pequenas ações do cotidiano e na luta do movimento. São nos fóruns, seminários, reuniões de sindicatos e dos movimentos sociais que estas mulheres obtêm seu pertencimento, reconhecimento, aumentam a autoestima e assim marcham em busca de seus diretos. Ou seja, com a participação política e o empoderamento das organizações e das mulheres, elas podem ocupar lugar de centralidade e propor mudança na esfera individual e coletiva.

\section{Considerações Finais}

A Marcha das Margaridas proporciona às mulheres do campo e da floresta visibilidade, participação política, reconhecimento, empoderamento e com isso há mudanças na sua vida pública e privada. Possibilitando valorizar a condição feminina em ambas as esferas, desse modo, o movimento busca realizar uma ruptura com a dominação masculina na esfera do mundo rural. Isso implica em atribuir importância às vozes e à atuação das mulheres do campo e da floresta.

Por meio da MM estas mulheres fortalecem o poder de organização e articulação que têm e adquirem unidade na luta a partir da integração dos movimentos nacional e regionais. $\mathrm{O}$ fato de se organizarem em rede, permite uma unificação das diversas nuances dos movimentos do campo e da floresta e a contemplação das diferentes demandas das mulheres em suas mais diversas condições.

Através da articulação em rede há possibilidade dessas mulheres serem sujeitos de sua história, desestabilizando a estrutura patriarcal que insiste em se 
perenizar na esfera do campo. Assim, denunciam a realidade do mundo rural, no que diz respeito às assimetrias de gênero e em suas questões sociais, econômicas e culturais mais gerais. Ao reivindicarem seus direitos pressionam o governo a voltar olhares e ações para a realidade do campo e da floresta e propõem pautas para a agenda do governo.

Apesar de algumas conquistas, a caminhada é longa e muito ainda falta para conquistar. Por isso elas seguem marchando!

\section{Referências Bibliográficas:}

AGUIAR, V. V. P. No Rastro da Marcha...construindo democracia. In: XXIX Congresso ALAS, 2013, Santiago do Chile. Crisis y Emergencias Sociales en América Latina, 2013.

AMORIM. É. O.; FIÚZA, A. L. C.; Filho, Barduni J.; Euclides, M. S. Sindicalizadas rurais e ativistas Políticas: fatores de empoderamento da mulher no meio rural? In: VIII Congresso Latino americano de Sociologia Rural, 2010, Recife. América Latina: realineamientos politicos y proyectos en disputa, 2010.

BAQUERO. Rute Vivian Angelo. Empoderamento: Instrumento de emancipação social? Uma discussão conceitual. REVISTA DEBATES, Porto Alegre, v. 6, n. 1, p.173-187, jan.-abr. 2012.

CARNEIRO, M. J. O rural como categoria de pensamento. Ruris, vol, 2, n. 1, março de 2008, pp. 9-38.

CARNEIRO, M. J. Em que consiste o familiar da agricultura familiar? COSTA, L.F.C; FLEXOR, G; SANTOS, R. (orgs) Mundo Rural Brasileiro. Ensaios interdisciplinares. Rio de Janeiro: Mauad X-EDUR, Seropédica, 2008a. pp. 255-269.

GOIS, M. N. Marcha das Margaridas: mulheres trabalhadoras rurais construindo igualdade de direitos, políticas públicas e cidadania. In: $X X$ Seminário Latino americano de Escuela de Trabajo Social. 2012. Argentina, pp $1-12$.

HOROCHOVSKI, R. R.; MEIRELLES, G. Problematizando o conceito de empoderamento. In: II Seminário Nacional Movimentos Sociais, Participação e Democracia, 2007, Florianópolis. Anais do II Seminário Nacional Movimentos Sociais, Participação e Democracia, 2007.

MARCHA DAS MARGARIDAS 2007, Cadernos de textos para estudos e debates. Elaboração: CONTAG, 2007.

FETAG'S, STTRS.

2011, Cadernos de textos para estudos e debates. Contag,

SCHERER-WARREN, Ilse. Das mobilizações às redes de movimentos sociais. Sociedade e Estado, Brasília, v. 21, n.1, p. 109-130, jan. /abr. 2006. 
A política dos movimentos sociais para o mundo rural. Estud. soc. agric, Rio de Janeiro, vol. 15, no. 1, 2007: p.5-22.

SILVA, B. G. A Marcha das Margaridas: resistências e permanências. Dissertação apresentada ao Programa de Pós-Graduação em Sociologia da Universidade de Brasília, 2008.

REVISTA MARCHA DAS MARGARIDAS 2007, Publicação da comissão Nacional de Mulheres Trabalhadoras Rurais da Contag, março 2008. 